
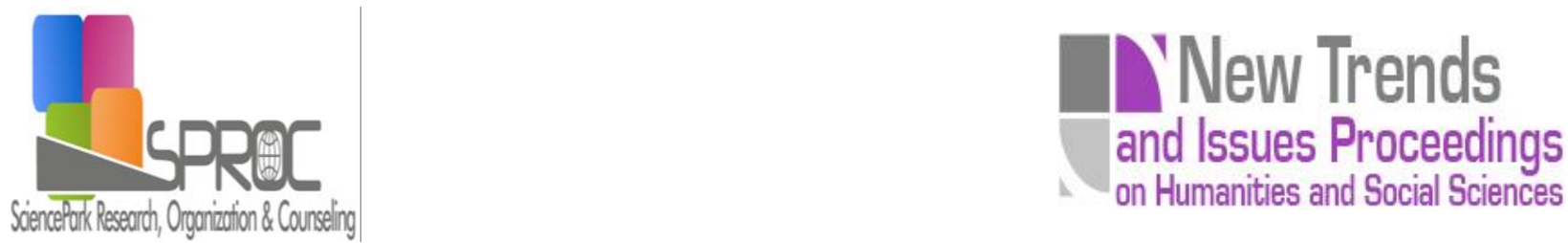

\title{
The power of metaphors in the educational discourse
}

Grigore-Dan Iordachescu *

Teodora Popescu

Crina Herteg

Suggested Citation:

Abstract 
1. Introduction

2. Literature Review 
3. Research Methodology

4. Results and Interpretation 
- 
5. Conclusions and Interpretation 
Acknowledgements

References 